\title{
Synthesis of Sulfonyl Fluoro Peptides by an Ugi Reaction
}

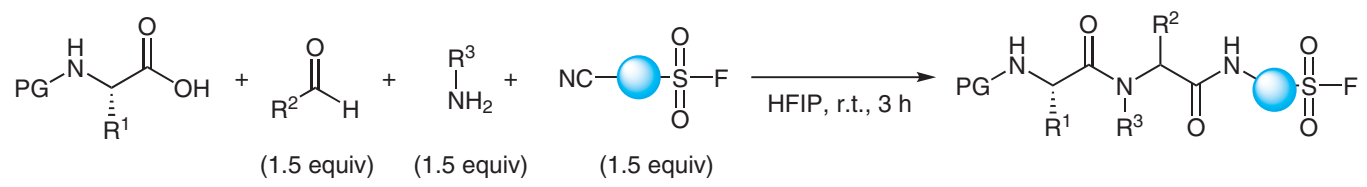

\section{Key words}

sulfonyl fluoro peptides

sulfonyl isocyanides click chemistry

Ugi reaction

\section{Selected examples:}

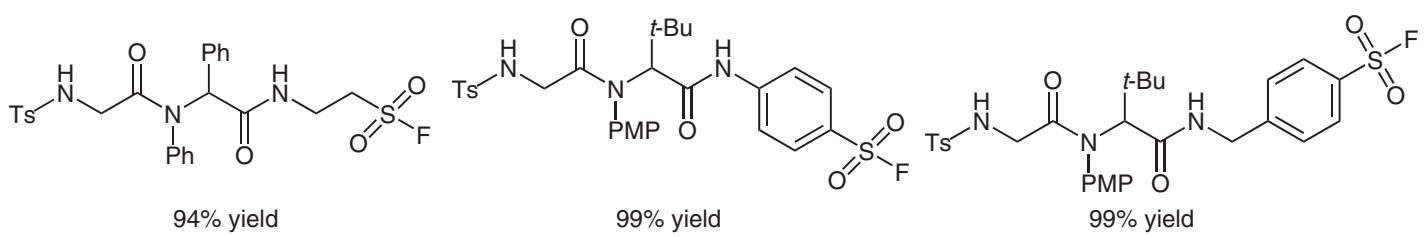

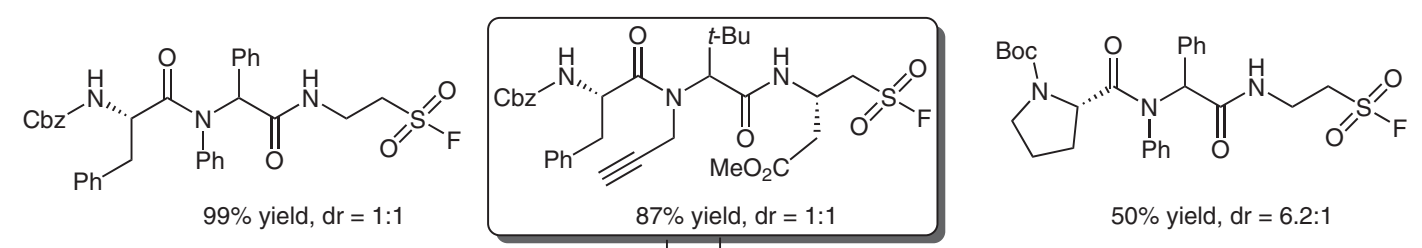

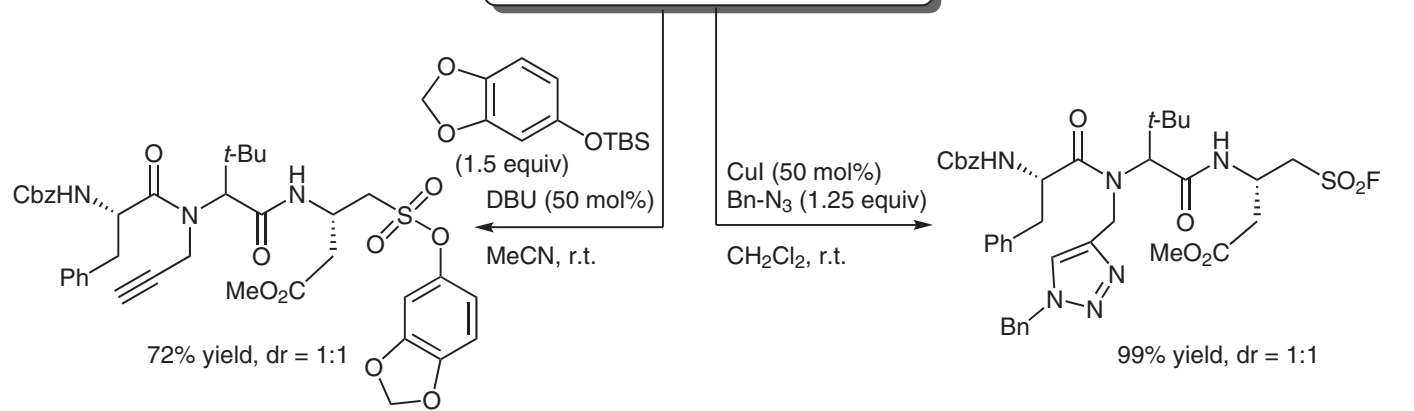

Significance: Sulfonyl fluoro amino acids could play significant roles in peptide modifications or the synthesis of bioactive peptides. The authors have developed a synthesis of sulfonyl fluoro peptides from sulfonyl isocyanide by using an Ugi reaction.
Comment: Various sulfonyl fluoro peptides were formed by the Ugi reaction. The resulting peptides could be used in click chemistry. 